\title{
Benign ve malign endometriyal patolojilerin klinik ve demografik özelliklerinin karşılaştırılması
}

\section{Comparation of clinic and demographic specialities of benign and malign pathologies of endometrium}

\author{
Dinçer Sümer*, Ayşe Gonca Yenicesu, Abdullah Boztosun, Fırat Çil, Yasin Bıyık, \\ Ahmet Emin Mutlu, Ali Yanık
}

Kadın Hastalıkları ve Doğum Anabilim Dalı (Dr. D. Sümer, Doç. Dr. A. G. Yenicesu, Yrd. Doç. Dr. A. Boztosun, Dr. F. Çil, Dr. Y. Bıyık, Prof. Dr. A. Yanık), Cumhuriyet Üniversitesi Tıp Fakültesi, TR-58140 Sivas, Kadın Hastalıkları ve Doğum Polikliniği (Dr. A. E. Mutlu), Sivas Devlet Hastanesi, TR-58030 Sivas

\section{Özet}

Amaç. $\mathrm{Bu}$ çalışma endometriyum kanseri ve benign endometriyal patolojilerin klinik ve demografik verilerini karşılaştırmayı ve endometriyum kanseri için risk faktörlerini belirlemeyi amaçlamaktadır. Yöntem. Kliniğimizde 2006-2010 yılları arasında endometrioid tip endometrial karsinom tanısı almış 31, endometriyal hiperplazi tanısı almış 29 ve proliferatif endometriyum tanısı almış 28 olmak üzere toplam 88 histerektomi olgusu çalışmaya dahil edildi. Olguların demografik ve takip bilgileri klinik dosyalarından elde edildi. Bulgular. Gebelik ve parite sayısı, diyabet varlığı ve sigara kullanımı arasında fark bulunamazken; ortalama yaş, endometriyal kalınlık değeri, menarş yaşı, postmenapozal olmak ve hipertansiyon varlığı endometriyum kanseri grubunda farklı bulunmuştur. Sonuç. Endometriyum kanseri hastaları daha erken yaşta menarş görmektedir ve çoğu postmenapozaldir İleri yaş, artmış endometriyal kalınlık ve hipertansiyon endometriyum kanseri için diğer risk faktörleridir.

Anahtar sözcükler: Endometriyum kanseri, risk faktörleri

\begin{abstract}
Aim. The objective of this study is to compare clinical and demographic data of benign and malign pathologies of endometrium and to describe risc factors for endomatrial carcinoma. Method. Eighty-eight patients which was hysterectomised in our clinic between 2006 and 2010 was included. Twenty eight of these has the diagnosis as 'proliferative endometrium', twenty nine as 'hyperplasia of endometrium', thirty-one as 'endometrioid type of endometrial carcinoma'. Data were collected from patient files retrospectively. Results. Pregnancy and parity rate, presence of diabetes mellitus and smoking were not altered for groups. Endometrial thickness and presence of hypertension were significantly higher for carcinoma group. Endometrial carcinoma patients were generally postmenauposal and had younger menarche age. Discussion. Advanced age, early menarche, increased endometrial thickness, hypertension and postmenapouse are risk factors for endometrial carcinoma.
\end{abstract}

Keywords: Endometrial carcinoma, risk factors

Geliş tarihi/Received: 02 Mayıs 2013; Kabul tarihi/Accepted: 06 Mart 2014

*İletişim adresi:

Dr. Dinçer Sümer, Kadın Hastalıkları ve Doğum Polikliniği, Bitlis Devlet Hastanesi, TR-13000 Bitlis. E-posta: dincersumer@yahoo.com 


\section{Giriș}

Endometriyal karsinom (EK) meme, akciğer ve kolon kanserinden sonra 4. sirada görülen kanser olup, kadın genital sisteminin ise gelişmiş ülkelerde en sık görülen malign tümörüdür (12.9 /100000). Dünyada 2008 yllında 287100 yeni hasta endometriyal karsinom tanısı almıştır [1]. Sağlık Bakanlığ 1 Kanserle Savaş Daire Başkanlığı'nın 20042006 yıllarını kapsayan 8 ildeki kanser verilerine göre Türkiye'de uterin korpus kanseri sayıs1 1373, kadınlardaki kanserler içinde rölatif oranı $\% 5$ tespit edilerek kadın genital sistemi tümörleri içerisinde birinci sıradadır [2]. Bu çalışmada endometriyum kanseri ve benign endometriyal patolojilerin klinik ve demografik verilerini karşılaştırmak ve endometriyum kanseri için risk faktörlerini belirlemek amaçlanmıştır.

\section{Gereç ve yöntem}

$\mathrm{Bu}$ çalışmada 2006-2010 yılları arasında kliniğimizde endometrioid tip endometrial karsinom tanısı almış 31, endometriyal hiperplazi tanısı almış 29 ve proliferatif endometriyum tanısı almış 28 olmak üzere toplam 88 olgu çalışmaya dahil edildi. Olgular yaş, endometriyal kalınlık değerleri, menarş yaşı, gebelik sayısı, parite sayısı, hipertansiyon ve diyabet varlığı, menapozal durum ve sigara kullanımı açısından karşılaştırıldı (Tablo 1). Demografik ve takip bilgileri klinik dosyalardan elde edildi. Etik Kurulu onayı alındı. Çalışmamızın verileri SPSS 14,0 programına yüklenerek verilerin değerlendirilmesinde ANOVA, Mann-Whitney $U$, student $T$ test ve Ki-kare testi uygulandı, yanılma düzeyi 0,05 olarak alındı.

\section{Bulgular}

Grupların yaş ortalamaları proliferatif endometriyum grubunda $46 \pm 3$, hiperplazi grubunda 46 \pm 6 , Endometriyum kanseri grubunda $59 \pm 10$ olarak bulunmuştur (p:0,001).

Endometriyal kalınlık değerleri proliferatif endometriyum grubunda 9,5 \pm , hiperplazi grubunda $11,9 \pm 3$ ve endometriyum kanseri grubunda $16 \pm 7 \mathrm{~mm}$ olarak bulunmuştur (p:0,006).

Menarş yaş1 proliferatif endometriyum grubunda $13 \pm 1$, hiperplazi grubunda $13 \pm 0$ ve endometriyum kanseri grubunda $12 \pm 1$ olarak bulunmuştur (p:0,006).

Gebelik sayıs1 prolifetaif endometriyum grubunda $4 \pm 2$, hiperplazi grubunda $4 \pm 2$, Endometriyum kanseri grubunda $5 \pm 3$ olarak bulunmuştur (p:0,343).

Parite sayis1 proliferatif endometriyum grubunda $3 \pm 1$, hiperplazi grubunda $3 \pm 1$, Endometriyum kanseri grubunda $4 \pm 2$ olarak bulunmuştur (p:0,313).

Menapozal durumları karşılaştırıldığında proliferatif endometriyum grubunda 3 hasta $(\% 10,7)$, hiperplazi grubunda 7 hasta $(\% 24,1)$ ve endometriyum kanseri grubunda 22 hasta $(\% 71)$ postmenapozal dönemdedir (p:0,005).

Proliferatif endometriyum grubundaki 28 hastanın 2'sinde $(\% 7,1)$ diyabetes mellitus tespit edilirken; endometriyal hiperplazi grubundaki 29 hastanın 7'sinde (\%24,1), endometriyum kanseri grubunda 10 hastada (\%33,3) tespit edilmiştir (p:0,051).

Proliferatif endometriyum grubunda 5 hastada $(\% 17,9)$ hipertansiyon tespit edilirken; endometriyal hiperplazi grubunda 8 hastada $(\% 27,6)$, endometriyum kanseri grubunda 17 hastada $(\% 56,7)$ tespit edilmiştir (p:0,005).

Proliferatif endometriyum grubunda 3 hastada $(\% 10,7)$ sigara kullanımı varken; endometriyal hiperplazi grubunda 5 hastada $(\% 17,2)$, endometriyum kanseri grubunda 4 hastada $(\% 14,8)$ tespit edilmiştir (p:0,777). 
Tablo 1. Grupların verilerinin karşılaştırılması.

\begin{tabular}{lllll}
\hline \multicolumn{1}{c}{ Parametre } & $\begin{array}{l}\text { Proliferatif } \\
\text { endometriyum (n:31) }\end{array}$ & $\begin{array}{l}\text { Endometriyal } \\
\text { hiperplazi (n:29) }\end{array}$ & $\begin{array}{l}\text { Endometriyal } \\
\text { karsinom (n:28) }\end{array}$ & Sonuç \\
\hline Yaş & $46 \pm 3$ & $46 \pm 6$ & $59 \pm 10$ & $\mathrm{p}: 0,001$ \\
Gravida & $4 \pm 2$ & $4 \pm 2$ & $5 \pm 3$ & $\mathrm{p}: 0,343$ \\
Parite & $3 \pm 1$ & $3 \pm 1$ & $4 \pm 2$ & $\mathrm{p}: 0,313$ \\
Endometriyal kalınlık (mm) & $9,5 \pm 3$ & $11,9 \pm 3$ & $16,0 \pm 7$ & $\mathrm{p}: 0,006$ \\
Menarş yaş1 & $13 \pm 1$ & $13 \pm 0$ & $12 \pm 1$ & $\mathrm{p}: 0,006$ \\
Menapozal durum (post-menapoz) & $\% 10,7$ & $\% 24,1$ & $\% 71$ & $\mathrm{p}: 0,005$ \\
Diabetes mellitus & $\% 7,1$ & $\% 24.1$ & $\% 33,3$ & $\mathrm{p}: 0.051$ \\
Hipertansiyon & $\% 17,9$ & $\% 27,6$ & $\% 56,7$ & $\mathrm{p}: 0,005$ \\
Sigara kullanımı & $\% 10,7$ & $\% 17,2$ & $\% 14,8$ & $\mathrm{p}: 0,777$ \\
\hline
\end{tabular}

\section{Tartışma}

Endometriyal karsinom kadın genital sisteminin gelişmiş ülkelerde en sık görülen malign tümörüdür [1]. Türkiye'de 2004 yılında 442, 2005 yılında 429, 2006 yılında 502 yeni tanı alan hasta olduğunu görmekteyiz ve ülkemizde sıklığı giderek artmaktadır [2].

Endometriyum kanseri genellikle 55-65 yaşlarında en sık görülmektedir. Kırk yaşından önce nadirdir [3]. Xu ve ark. [4] yaptıkları çalışmada ortalama yaşı 55,2, Sorosky ve ark. [5] 61, Göksedef ve ark. [6] 56,2 $\pm 9,6$, Aka ve ark. [7] 60,8 olarak bulmuşlardır. Çalışmamızda grupların yaş ortalamaları proliferatif endometriyum grubunda $46 \pm 3$, hiperplazi grubunda $46 \pm 6$, Endometriyum kanseri grubunda $59 \pm 10$ olarak bulunmuştur. Karsinom anlamlı olarak daha ileri yaşta görülmektedir.

Transvajinal ultrasonografide artmış endometriyal kalınlık EK ile ilişkilidir [8, 9]. Endometriyal karsinom endometriyal kalınlığın $5 \mathrm{~mm}$ altında olduğu hastalarda nadiren görülmektedir. 5mm eşik değer olarak alındığında negatif prediktif değer \%99 iken, $4 \mathrm{~mm}$ alındığında \%100 olmaktadır. Karsinomların \%96'sında kalınlık 5mmnin üzerinde tespit edilmiştir [10-13]. Yapılan çalışmalarda postmenopozal kanamalı ve histopatolojik tanıs1 endometriyum kanseri olarak saptanan kadınlarda ise ortalama endometriyal kalınlık 13,9-21,1 mm tespit edilmiştir [14]. Aka ve ark. [7] endometrioid adenokarsinomlarda endometrial kalınlığ $12,3 \pm 5,1$ olarak belirtmiştir. Endometriyal kalınlık değerleri proliferatif endometriyum grubunda $9,5 \pm 3$, hiperplazi grubunda $11,9 \pm 3$ ve endometriyum kanseri grubunda $16 \pm 7 \mathrm{~mm}$ olarak bulunmuştur. Karsinom vakalarımızın 3 tanesinde endometriyal kalınlık 5 mm'nin altındadır. Endometriyal kalınlık kanser hastalarında anlamlı olarak diğer gruplardan fazladır.

Karşılanmamış östrojen teorisi endometrioid karsinomların gelişiminde önemli yer tutmaktadır. Erken yaşta menarş ve ileri yaşta menapoz uzamış östrojen uyarımına bağlı olarak endometriyal karsinom riskini arttırmaktadır [4, 15]. Pek çok araştırmacı erken menarş ve geç menopozun endometriyum kanseri acısından risk faktörü olduğunu belirtmiştir [16]. Xu ve ark. [4] menarş yaşı arttıkça karsinom riskinin azaldığını belirtmişlerdir. Menarş yaşı proliferatif endometriyum grubunda $13 \pm 1$, hiperplazi grubunda $13 \pm 0$ ve endometriyum kanseri grubunda $12 \pm 1$ olarak bulunmuştur. Karsinom grubunda anlamlı olarak erken yaşta menarş söz konusudur.

Nulligravida ve nulliparite endometriyal karsinom riskini arttırmaktadır [17-20]. Xu ve ark. [4], bu artışı 1,93 kat olarak belirtmişlerdir. Miada ulaşsın veya ulaşmasın gebelik endometrial kanser riskini azaltmaktadır [4]. Yüksek parite endometrial kanserden ölümü azaltmaktadır [21]. Göksedef ve ark. [6] adenokarsinom hastalarında gravida ve parite sayısını 3 olarak belirtirken, Aka ve ark. [7] sirasiyla 5,2 $\pm 3,3$ ve $3,8 \pm 2,8$ olarak belirtmişlerdir. Çalımamızda gebelik sayısı proliferatif endometriyum grubunda $4 \pm 2$, hiperplazi grubunda $4 \pm 2$, endometriyum kanseri grubunda $5 \pm 3$ olarak bulunmuştur. Parite sayıs1 proliferatif endometriyum grubunda $3 \pm 1$, hiperplazi grubunda $3 \pm 1$, Endometriyum kanseri grubunda $4 \pm 2$ olarak bulunmuştur.

Menapozal durumları karşılaştırıldığında proliferatif endometriyum grubunda 3 hasta $(\% 10,7)$, hiperplazi grubunda 7 hasta $(\% 24,1)$ ve endometriyum kanseri grubunda 22 
hasta(\%71) postmenapozal dönemdedir. Sorosky ve ark. [10] hastaların yaklaşık \%20'sinin premenapozal olduğu belirtmiştir. Bulgularımız literatür ile uyumludur.

Diyabet endometriyal karsinom riskini arttırmaktadır. Noto ve ark. [23] yaptıkları çalışmada 3,43 kat, Friberg ve ark. [24] yayımladıkları meta analizde 2,10 kat arttırdığını bulmuşlardır. Nicholas ve ark. [25] 490 hasta içeren çalışmalarında hastaların \%26'sinde diyabet olduğunu belirtmişlerdir. Aka ve ark. [7] endometrioid tip karsinomda diyabet birlikteliğini \%17,3 olarak belirtmişlerdir. Proliferatif endometriyum grubundaki 28 hastanın 2 sinde $(\% 7,1)$ diyabetes mellitus tespit edilirken; endometriyal hiperplazi grubundaki 29 hastanın 7'sinde $(\% 24,1)$, endometriyum kanseri grubunda 10 hastada $(\% 33,3)$ tespit edilmiştir. Karsinom grubunda daha çok sayıdaki hastada diyabet tespit edilmekle birlikte diğer gruplarla arasında istatistiksel olarak anlamlı farklılık bulunamamıştır.

Hipertansiyonun endometriyal karsinom ile ilişkisi bilinmekle birlikte genellikle obezite ve diyabete eşlik etmesinden dolayı ve neden-sonuç ilişkisi net olarak ortaya konulamamasından dolayı bağımsız risk faktörü olarak desteklenmemektedir $[10,15]$. Aka ve ark. [7] endometrioid tip karsinomda hipertansiyon oranını \%19,5 olarak belirtmişlerdir. Nicholas ve ark. [25] 490 hasta içeren çalışmasında hastaların \%47'sinde hipertansiyon olduğunu belirtmiştir. Proliferatif endometriyum grubunda 5 hastada $(\% 17,9)$ hipertansiyon tespit edilirken; endometriyal hiperplazi grubunda 8 hastada (\%27,6), endometriyum kanseri grubunda 17 hastada $(\% 56,7)$ tespit edilmiştir. Hipertansiyon anlamlı olarak endometriyal karsinom grubunda yüksek orandadır. Bulgularımız literatürü desteklemekle birlikte neden-sonuç ilişkisini ortaya koyamamaktadır.

Sigara kullanımının endometriyal kansere karşı koruyucu etkisi olduğunu belirten çalışmalar mevcuttur [26, 27]. Nicholas ve ark. [25] 490 hasta içeren çalışmalarında hastaların \%11'sinde sigara kullanımı olduğunu fakat sigara kullanımı ile sağkalım arasında ilişki bulunmadığını belirtmişlerdir. Proliferatif endometriyum grubunda 3 hastada $(\% 10,7)$ sigara kullanımı varken; endometriyal hiperplazi grubunda 5 hastada $(\% 17,2)$, endometriyum kanseri grubunda 4 hastada $(\% 14,8)$ tespit edilmiştir ve gruplar arasında anlamlı farklılık bulunamamışır.

Sonuç olarak çalışmamızdaki veriler ışığında ilerlemiş yaş, erken yaşta menarş, endometriyal kalınlık artışı, hipertansiyon varlığı ve postmenapozal dönemde olmak endometriyum kanseri için risk faktörü olarak kabul edilebilir.

\section{Kaynaklar}

1. Jemal A, Bray F, Center MM, Ferlay J, Ward E, Forman D. Global cancer statistics. CA Cancer J Clin 2011; 61: 69-90.

2. Sağlık Bakanlığı Türkiye Halk Sağlığı Kurumu Kanser Daire Başkanlığı 20042006 Y1lları Türkiye Kanser İnsidans1 http://kanser.gov.tr/folders/file/8iL-2006SON.pdf

3. Kumar V, Abbas A. Robbins and Cotran patologic basis of disease eight edition Philadelphia saunders elsevier 2010; pp: 1005-65.

4. Xu WH, Xiang YB, Ruan ZX, Zheng W, Cheng JR, Dai Q, Gao YT, Shu XO. Menstrual and reproductive factors and endometrial cancer risk: Results from a population-based case-control study in urban Shanghai. Int J Cancer 2004; 108: 613-9.

5. Sorosky JI. Endometrial cancer. Obstet Gynecol 2008; 111: 436-47.

6. Göksedef BP, Akbayır Ö, Çorbacıŏglu A, Güraslan H, Şencan F, Erol O, Çetin A. Comparison of preoperative endometrial biopsy grade and final pathologic diagnosis in patients with endometrioid endometrial cancer. J Turkish-German Gynecol Assoc 2012; 13: 106-10.

7. Aka N, Civak LÜ, Köse G, Türkay Ü, Karayel S, Aksu Ö. Endometrial Kanser: 58 Olguda Tanı ve Tedavi Deneyimi. Türk Jinekolojik Onkoloji Dergisi 2007; 
10: $16-22$.

8. Tabor A, Watt HC, Wald NJ. Endometrial thickness as a test for endometrial cancer in women with postmenopausal vaginal bleeding. Obstet Gynecol 2002; 99: 663-70.

9. Timmermans A, Opmeer BC, Khan KS, Bachmann LM, Epstein E, Clark TJ, Gupta JK, Bakour SH, van den Bosch T, van Doorn HC, Cameron ST, Giusa MG, Dessole S, Dijkhuizen FP, Ter Riet G, Mol BW. Endometrial thickness measurement for detecting endometrial cancer in women with postmenopausal bleeding: a systematic review and meta-analysis. Obstet Gynecol 2010; 116: 1607.

10. Sorosky, Joel I. Endometrial Cancer. Obstetrics \& Gynecology 2012; 120: 38397.

11. Langer RD, Pierce JJ, O'Hanlan KA, Johnson SR, Espeland MA, Trabal JF, Barnabei VM, Merino MJ, Scully RE. Transvaginal Ultrasonography Compared With Endometrial Biopsy For The Detection Of Endometrial Disease. Postmenopausal Estrogen/Progestin Interventions Trial. N Engl J Med 1997; 337: 1792-8.

12. Gull B, Carlsson S, Karlsson B, Ylöstalo P, Milsom I, Granberg S. Transvaginal ultrasonography of the endometrium in women with postmenopausal bleeding: is it always necessary to perform an endometrial biopsy? Am J Obstet Gynecol 2000; 182: 509-15.

13. Smith-Bindman R, Kerlikowske K, Feldstein VA, Subak L, Scheidler J, Segal M, Brand R, Grady D. Endovaginal Ultrasound To Exclude Endometrial Cancer And Other Endometrial Abnormalities. Jama 1998; 280: 1510-7.

14. Granberg S, Karlsson B, Wikland M, Gull B: Uterus ve Endometriyum Hastalıklarının Transvajinal Sonografisi. In: Fleischer AC, Manning FA, Jeanty P, Romero R, (eds.) Obstetrik ve Jinekolojide Sonografi, beşinci baskı, Ulusal Tip Kitabevi 2000; 851-68.

15. Berek SJ. Berek\&novak's Gynecology 14th edition, Philadelphia William\&Wilkins, 2007.

16. Erkun E: Hormon Replasman Tedavisi ve Endometrium Kanseri. In: Ertungealp E, Seyisoğlu H, (eds.) Menopoz ve Osteoporoz, birinci baskı, Menopoz ve Osteoporoz Derneği, İstanbul, 2000; 283-6.

17. Chamlian DL, Taylor HB. Endometrial hyperplasia in young women. Obstet Gynecol 1970; 36: 659-66.

18. Parazzini F, Negri E, La Vecchia C, Benzi G, Chiaffarino F, Polatti A, Francheschi S. Role of reproductive factors on the risk of endometrial cancer. Int J Cancer 1998; 76: 784-6.

19. Parazzini F, La Vecchia C, Negri E, Fedele L, Balotta F. Reproductive factors and risk of endometrial cancer. Am J Obstet Gynecol 1991; 164: 522-7.

20. McPherson CP, Sellers TA, Potter JD, Bostick RM, Folsom AR. Reproductive factors and risk of endometrial cancer. The Iowa Women's Health Study. Am J Epidemiol 1996; 143: 1195-202.

21. Løchen ML, Lund E. Childbearing and mortality from cancer of the corpus uteri. Acta Obstet Gynecol Scand 1997; 76: 373-7.

22. Gerber J, Sozański L, Suchocki S. The risk factors of endometrial cancer. Ginekol Pol 2001; 72(12A): 1418-22.

23. Noto H, Osame K, Sasazuki T, Noda M. Substantially increased risk of cancer in patients with diabetes mellitus: a systematic review and meta-analysis of epidemiologic evidence in Japan. J Diabetes Complications 2010; 24: 345-53.

24. Friberg E, Orsini N, Mantzoros CS, Wolk A. Diabetes mellitus and risk of endometrial cancer: a meta-analysis. Diabetologia 2007; 50: 1365-74.

25. Nicholas Z, Hu N, Ying J, Soisson P, Dodson M, Gaffney DK. Impact of Comorbid Conditions on Survival in Endometrial Cancer. Am J Clin Oncol 2012 Dec 13 
26. Brinton LA, Lacey JV Jr, Devesa SS: Epidemiology of uterine corpus cancer. In Gershenson DM, McGuire WP, Gore M, Quinn MA, Thomas G. (eds): Gynecologic Cancer: Controversies in Management. New York, Churchill Livingstone, 2004; pp: 190.

27. Viswanathan AN1, Feskanich D, De Vivo I, Hunter DJ, Barbieri RL, Rosner B, Colditz GA, Hankinson SE. Smoking and the risk of endometrial cancer: Results from the Nurses' Health Study. Int J Cancer 2005; 114: 996-1001. 